theme 1

theory

author(s)

\title{
Design Education - The Case Study Daciano da Costa
}

This paper, which stems from a developing research project, aims to disseminate among the international scientific community the thought of Daciano da Costa (1930-2005) given the importance he conferred to Drawing in the Design Process, throughout his teaching career and his professional practice as a reference figure in the Design of the twentieth century in Portugal. We cannot speak about Portuguese Design without referring to Daciano da Costa.

Daciano da Costa played a pioneer role on Design's theory fundaments in Portugal and an important pedagogic role as a teacher. He created and implemented the Design Graduation Degree Plan, established in 1991 at the Faculty of Architecture, Technical University of Lisbon, being its coordinator since then until 2003.

His pedagogical action in teaching the Drawing subject demonstrates the importance he ascribed to it in Design learning.

Daciano's drawing teaching method was remarkably operational stimulating invention through a methodology that enhances and favours the operational Drawing characteristics within the Design process.

We intend to establish the relations between Design and Drawing. The relevance of Drawing in the conceptual process in Design will be based on the Case Study Daciano da Costa. The Drawing Teaching Method implemented by Daciano da Costa, because of his own methodological specificity, presents a critical and operative character which confers it a permanent actuality in Design training.

keywords design education, Daciano da Costa, drawing, design process

\section{Introduction}

We analyse the thinking of Daciano da Costa concerning the important role that he conferred to Drawing, throughout his teaching career and his achievement as a national reference figure of Design in the XX century.

In this study we consider the close relationship between Drawing and Design.

The relevance of drawing in the act of designing as stimulating instrument when sketching the first ideas and as critical verification of the several hypotheses.

His pedagogical action in teaching the Drawing subject demonstrates the importance he ascribed to it in Design learning.

As a professor, Daciano da Costa considered essential to provide students to understand the drawing importance in the conceptual Design process. Professor at the Architecture Faculty in Lisbon from 1977 to 2003, contributed decisively for the formation of many architects and designers. 
theme 1

theory

Figure 1. Daciano da Costa (1930-2005) strand 2

design education in art, craft, technology, and other traditions

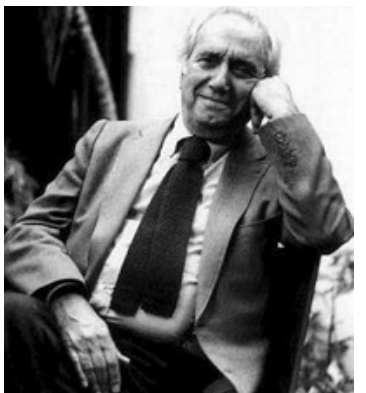

Before Daciano, the used teaching methods were mostly based upon old fashioned academic rules from the french Beaux Arts which have been spread and used in European Art Schools. There wasn't much correlation between drawing studies and project needs, project methodologies. He introduced in Portugal an innovative teaching methodology concerned with project problems and solutions through the training of his students to become future professionals within the new times paradigm.

Daciano imprinted a strong operative character to Drawing teaching, encouraging invention through a methodology that emphasizes and focuses on the operational characteristics of Drawing involved in the conception process in Design.

Design is inseparable from project, from project methodology, and Drawing assumes itself as an indispensable tool in the Design process.

The issue focuses on the relationship between Drawing and Project, and the importance that Drawing acquires in the conceptual act of the Design project, as a booster instrument when registering the first ideas, and as verification of the several hypotheses.

Being aware of the complexity of project making as intellectual ability to imagine what doesn't exist yet, Drawing appears as the project tool that enables the possibility of making the idea visible.

As the designer has to conceive and develop solutions for precise problems which may be of very different nature, Drawing presents itself as an operative support for problems solving in the Design conceptual process. Due to its operative characteristics, the importance of Drawing assumes itself as a wide sense, providing the act of drawing with the ability of being a means with multiple resources and a basis for the conceptual process underlying the practice of Design.

We find reference to Drawing in the very origin of the word Design. 'Designare', is a Latin verbal form, which covers both the meaning of 'to designate something' and of 'to draw something'. In its origins the term already has a double sense: a more abstract aspect of 'to attribute, to conceive, to project' and another one of more concrete nature of 'to register, to configure, to form'.

On a direct connection with our reasoning, Francisco Providência, in the text with the suggestive title "desire, drawing, designio", writes: "In our own view, design is the manifestation of drawing, due to the desire to pursue a 'designio'." (1999: 134)

Design adds intention to Drawing: to imagine, to conceive and to assist in the achievement of solutions for practical problems, which can be of very different nature. Ezio Manzini, in The Material of Invention, refers the issue between the "thinkable" and the "possible", which is always underlying the Design process, considering it neither simple nor linear. (1993: 5) Bryan Lawson also characterizes this process as "highly complex and 
sophisticated." (1995: 67)

During all the complex process which goes from one imagined object to its implementation, designer has one essential media to help him on developing the idea Drawing. Drawing holds, in itself, the making visible quality of the whole mental process underlying the conceiving stage, from the first sketches of a vague idea to the object to create final form. The complexity, characteristic of the transition from the idea to its materialization, is related to the actual extent of Design where a number of factors come into play, such as the ability to understand the context and imagine the solutions, the ability to know and take advantage of the processes and materials as means or vehicles through which the solution is materialized, the ability to transform ideas into appropriate forms, having in mind the limits and material possibilities.

Daciano's methodology emphasized these points, leading students to an understanding of the surrounding reality through different kinds of sketches in distinctive scales, taking advantage of the materiality of objects, textures, structures, being colour subjacent to the all process. This way, the student was conducted to incorporate the knowledge obtained through the process of observation and comprehensive drawing, always controlled, in the future transposition for the creation act, for the design project.

This concept of 'knowledge through drawing' was an important aspect on Daciano's life. He considered imperative that all design professionals should draw on a daily basis (Costa 1994: 23). His travel drawings constitute an excellent example of this 'acquisition knowledge process' through sketching what he observed, registering the moment, the atmosphere, the whole and the detail, studying built structures or city and landscape ambiances.

The development of this ability, analysing and synthetizing from direct observation, was one of the objectives of his drawing teaching, implementing this training by the regular use of a sketch book by his students, in a daily bases, motivating them to see and learn through drawing.

Within the complex process which takes place from how to imagine an object until its materialization, the designer can use drawing as an important tool to help him developing the idea.

Daciano's understanding about Drawing as an operative support in the conceptual process. This attitude comes across the concept of Drawing as mental activity, which uses the hand as an extension of the brain.

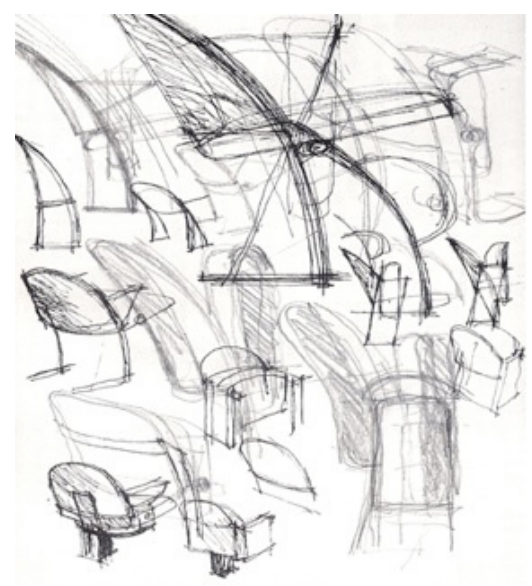

Figure 2.

Sketches for a chair, 1994 . Daciano da Costa (1998: 154) 
The search for solutions, even for simple problems, implies that Drawing studies in detail each phase of the process for obtaining the result we seek for. The complexity of the required drawings emerges as the designer approaches the solutions which he considers ideal or that are possible.

To Munari "Throughout the project process the designer uses different types of drawings, from the simple sketch to fix a thought useful to the project, to the construction drawings, the perspectives, the axonometries, the exploded drawings." (1993: 67)

During the conception phase we should not disregard the importance of a trace, of a scribble, of a sketch. They all can contribute to the development of the idea. The act of drawing allows that the reasonings and thoughts we have developed can be gradually translated and decoded throughout the drawn lines. Somehow we debate ourselves with our own ideas in the paper space. We scratch, we draw, we overwrite features, we configure, we represent, we visualize, giving physical form to our thinking. There is a direct link between the thinking and the hand that performs the drawing. The hand as an extension of the brain, of the reasoning.

About Design methodology, Nigel Cross states that "drawings are a key feature of the design process. At the early stages of the process, the drawings that the designer makes are not usually meant to be communications to anyone else. Essentially, they are communications with oneself, a kind of thinking aloud." and concludes: "The conceptual thinking processes of the designer are based on the development of the ideas through their external expression in sketches" (2005: 9-20).

The impact of new materials and production processes, together with the changing nature of society and the alliance between technology and design, present designers with considerable challenges (Sparke 2004: 3).

The fact of using new technologies doesn't invalidate the important role played by manual Drawing, both at the initial stage of recording the first ideas and during their subsequent development and in the critical analysis of the different hypotheses.

Given the difficulties of project process as an ability to imagine what doesn't exist, Drawing appears to be the project tool that enables the idea to become visible. Drawing mediates between thought and action, expresses the thought by images that allow us to visualize the future conception.

Baeza writes in the introduction of one of his books, that its title, "Thinking with the Hands", is intended to make clear that "the creative work requires both hands and head. (...) This Thinking with the hands is inspired on the bright image of Saramago's novel The Cave when he states that creators have a sort of little brains in their fingertips" (2011: 11).

To study Drawing understood as a bearer and an intermediate of the idea and of the project, means to deepen its values in order to explore the multiple meanings contained in graphic language, understanding, directly, through the 'reading' of the Drawing, the generating idea of the project.

In a previous research (Moreira da Silva 2010: 101) approaching the subject, we concluded that drawing accomplishes the most different objectives, such as:

A way to communicate; means of discovery; process of interiorization; graphic method of study; observation and registering process; research tool; privileged means for the communication of ideas; link in the mental and creative process.

So, the importance of Drawing assumes a broad sense, conferring to the act of drawing the ability to become a means of multiple resources to practice the discipline of Design. Defending a constant learning and a permanent adaptation to new paradigms Daciano 
stated: "From an educational formation we can only expect that it teaches us to learn and we all will have to go back to acquire new skills, as a preparation for the new tasks that the developments in technology and social evolution will make to emerge." (Costa 1998: 42) We must not forget that the future of education in Design must necessarily fit in the new realities, particularly given the importance that recent computer technologies assume within the process of Design project. In the early ' 90 , Daciano was already aware of the growing importance of computer tools to support the practice of the designer. In his communication on the III Design Journeys, affirmed: "Informatics (CAD systems) permits to exhaust alternatives and accelerate the decision-making in project activity". (Costa 1998: 38) In fact the new information technologies offer the designer new ways, allowing him to save time and facilitating many of the daily practice tasks, even becoming indispensable in many work phases. However, they do not replace manual drawing, which continues to assume a 'chameleon' shape during the various historical periods, in a constant time adaptation, and, especially by incorporating a critical dimension in Design's conception process.

\section{Conclusion}

In the future, Design teaching should pass through a systematic approach to Drawing in order to highlight and analyse the flexibility with which it adapts itself to various purposes, fulfilling effectively a wide range of intentions, in a constant and vital adaptation to the continuous changes in the teaching and in the practice of the student and of the designer, given the new techniques and technologies.

Despite the paradigm shift required by changing times and as above exposed, we believe that Drawing must remain inseparable from the designers training and professional practice assuming an essential operating support in the project activity which continues being the Design basis.

In order to validate this assumption, the current research, inspired and consolidated by the case study Daciano da Costa, can constitute a contribution for the understanding of the importance of Drawing's permanence as the foundation of the Design conceptual process.

\section{References}

Baeza, A. C. (2011) Pensar com as Mãos, Lisboa: Caleidoscópio.

Costa, D. (1994) Croquis de Viagem, Daciano da Costa, Travel Drawings, Lisboa: Livros Horizonte. Costa, D. (1998) Design e Mal-Estar, Lisboa: Centro Português de Design.

Cross, N. (2005) Engineering Design Methods, Strategies for Product Design, Chichester, England: John Wiley \& Sons Ltd.

Lawson, B. (1995) How Designers Think - The Designers Process Demystified, Oxford:

Elsevier Architectural Press.

Manzini, E. (1993) A Matéria da Invenção, Lisboa: CPD.

Moreira da Silva, A. (2010) De Sansedoni a Vasari: um contributo para o estudo

do Desenho como fundamento do processo conceptual em Arquitectura, Lisboa:

Universidade Lusíada Editora.

Munari, B. (1993) Das Coisas Nascem Coisas, Lisboa: Edições 70.

Providência, F. (1999) 'Desejo, Desenho, Desígnio', Anuário do Centro Português de

Design, Design é Tudo, Lisboa: CPD, p.134.

Sparke, P. (2004) An Introduction to Design and Culture, London: Routledge. 